\title{
Lignocellulosic Residues from the Brazilian Juice Processing Industry as Novel Sustainable Sources for Bioenergy Production: Preliminary Assessment Using Physicochemical Characteristics
}

\author{
José L. F. Alves, ${ }^{\oplus a}$ Emmely O. da Trindade, ${ }^{b}$ Jean C. G. da Silva, ${ }^{\oplus a}$ \\ Guilherme D. Mumbach, ${ }^{\oplus a}$ Ricardo F. Alves, ${ }^{\circledR c}$ José M. Barbosa Filho, ${ }^{\circledR * d}$ \\ Petrônio F. de Athayde-Filho ${ }^{b}$ and Rennio F. de Sena ${ }^{e}$ \\ ${ }^{a}$ Departamento de Engenharia Química e Engenharia de Alimentos, \\ Universidade Federal de Santa Catarina, 88040-900 Florianópolis-SC, Brazil \\ ${ }^{b}$ Departamento de Química, Universidade Federal da Paraíba, 58051-900 João Pessoa-PB, Brazil \\ 'Unidade Acadêmica de Engenharia de Materiais, Universidade Federal de Campina Grande, \\ 58429-900 Campina Grande-PB, Brazil \\ ${ }^{d}$ Departamento de Ciências Farmacêuticas, Universidade Federal da Paraíba, \\ 58051-900 João Pessoa-PB, Brazil \\ ${ }^{e}$ Laboratório de Carvão Ativado, Departamento de Engenharia Química, \\ Universidade Federal da Paraíba, 58051-900 João Pessoa-PB, Brazil
}

\begin{abstract}
This work aims to investigate the energy-related characteristics of apple bagasse, orange bagasse and cashew-apple bagasse to identify their potential as bioenergy feedstocks. For this, a detailed characterization was performed, including proximate analysis, ultimate analysis, atomic molar ratio, heating values, chemical composition, bulk density, bioenergy density, fuel-value-index (FVI), fossil fuel equivalence and potential $\mathrm{CO}_{2}$ retention. Proximate composition revealed moisture, volatile matter, fixed carbon and ash contents in the range of 7.8-9.3\%, 67.1-74.2\%, 16.2-22.0\% and 1.6-5.7\%, respectively. Typical values for carbon (44.8-49.9 wt.\%), hydrogen (5.5-6.6 wt.\%) and oxygen (40.1-44.2 wt.\%), with low sulfur $(<0.1$ wt.\%) and nitrogen $(<2.7$ wt. $\%)$ contents were found. In regard to bulk density $\left(237.7-554 \mathrm{~kg} \mathrm{~m}^{-3}\right)$ and bioenergy density $\left(3.93-10.1 \mathrm{GJ} \mathrm{m}^{-3}\right)$, juice processing residues have substantial values when compared with well-known lignocellulosic residues. Recoverable energy potential from the juice processing residues varied from 15.24 to $17.03 \mathrm{MJ} \mathrm{kg}^{-1}$. From FVI analysis, apple bagasse is expected to be more suitable for thermochemical processing. Orange bagasse, on the other hand, has the highest equivalent in fossil fuel volume. Consequently, its use as solid fuel may lead to a decrease in $\mathrm{CO}_{2}$ emissions from reference fuels.
\end{abstract}

Keywords: juice industry, lignocellulosic residues, physicochemical characterization, bioenergy production

\section{Introduction}

In recent years, the interest in the use of biomass as a sustainable substitute for fossil fuel replacement has intensified due to its envisaged role in reducing greenhouse gas emissions, especially carbon dioxide $\left(\mathrm{CO}_{2}\right)^{1,2}$ Thus, the production of bioenergy (energy from biomass) extracted from the lignocellulosic residues presents an interesting niche for research and development.

*e-mail: jbarbosa@1tf.ufpb.br
Efforts are being put towards searching for appropriate and abundant biomass residues easily convertible into bioenergy, which is a crucial factor to achieving viability for large-scale bioenergy generation. Related studies aiming to identify new bioenergy feedstocks are found in the literature. ${ }^{3-8}$ For this purpose, information about physicochemical properties from lignocellulosic biomass is a crucial factor in revealing its potential as a feedstock in thermochemical processes. For instance, herbaceous biomass, ${ }^{3}$ coffee wastes, ${ }^{4}$ forest waste,${ }^{4}$ cassava waste, ${ }^{5}$ fish scales, ${ }^{6}$ pineapple crown leaves, ${ }^{7}$ biosolids, ${ }^{8}$ and 
açaí kernels, ${ }^{8}$ were suggested as potential feedstocks for bioenergy generation.

The Brazilian fruit juice industry has a leading global position in the food sector, especially due to privileged agro-ecological conditions found in Brazil. Fruit bagasse (or pomace) commonly appears as a by-product in the industrial processing of fruit juices. Therefore, large amounts of these lignocellulosic residues occur regularly. According to the Food and Agriculture Organization of the United Nations (FAO), ${ }^{9}$ worldwide apple production was $83,139,326$ tonnes in 2017, of which 1,300,943 tonnes resulted from Brazilian production (about $1.56 \%$ of the world production). In apple processing industries, after juice extraction, total apple bagasse produced represents $30-35 \%$ of processed fruit's gross weight; ${ }^{10,11}$ consequently, in Brazil, thousands of tons of biomass are generated annually in the form of agroindustrial residue with no commercial destination. Regarding orange production in 2017, world production exceeded 73,313,089 tonnes in 2017 according to the FAO, ${ }^{9}$ with Brazil as a world leader responsible for about $23.82 \%$ (17,459,908 tonnes) of global output. Orange bagasse represents about $50 \%$ of total fruit weight, ${ }^{12}$ and so it is accumulated in large amounts during the harvesting and industrial processing of oranges. Brazil is also a world leader in cashew-apple (Anacardium occidentale) production, with approximately $88 \%$ of global output in 2017. ${ }^{9}$ Almost the entire production is concentrated in Brazil's northeastern region, with the states of Ceará, Piauí and Rio Grande do Norte particularly dependent on cashew's agribusiness. ${ }^{13,14}$ Cashew-apple bagasse is the solid by-product obtained after juice extraction from the cashew-apple fruit, representing approximately $20 \%$ of its total weight. ${ }^{13,14}$ The direct dumping of lignocellulosic residues from the juice industry in the environment can have several adverse impacts such as greenhouse gases, secondary pollution and adverse effects on human health. ${ }^{11}$

The Brazilian government, through its National Solid Waste Policy (PNRS) efforts, has encouraged the use of thermochemical conversion pathways as effective methods for recovering bioenergy from organic solid wastes, securing minimization of environmental pollution simultaneous with environment-friendly use of these wastes for bioenergy production. ${ }^{15,16}$ In this context, the thermal conversion appears as a viable option for harnessing bioenergy from lignocellulosic residues such as apple bagasse, orange bagasse, and cashew-apple bagasse, which are often unexplored by-products from the fruit juice processing industries in Brazil. Only a few studies can be found in the literature concerning the evaluation of the properties of juice processing residues (especially apple bagasse, orange bagasse and cashew-apple bagasse, mostly available in
Brazil) as biofuels for thermochemical processing, ${ }^{8}$ and these studies often do not present a detailed analysis of the energy-related properties. A comprehensive evaluation of biomass characteristics is an essential step for adapting thermochemical equipment, ${ }^{17}$ such as burners or boilers, which were usually designed for the conversion of firewood or coal into heat or energy. In the work presented here, for the first time, an attempt was made to investigate the energyrelated characteristics of typical lignocellulosic residues derived from the Brazilian juice processing industry.

The main goal of the present study was to determine the potential of apple bagasse, orange bagasse and cashew-apple bagasse as alternative biofuels applied in thermochemical processes, in terms of physicochemical and bioenergy properties. For this purpose, physicochemical properties, including ultimate proximate analysis, ultimate analysis, calorific values and bulk density, were determined using established procedures. Physicochemical analyses selected to evaluate the bioenergy potential of feedstocks are usually found in related scientific literature. ${ }^{17-19}$ In line with physicochemical properties, other bioenergy-related parameters were estimated, including atomic molar ratio, biochemical composition, low heating value, bioenergy density, fuel value index, fossil fuel equivalence and potential $\mathrm{CO}_{2}$ retention. Additionally, biofuel properties for juice processing residues were compared with those of typical biomass for bioenergy purposes. This study is expected to provide new insights into the valorization of typical lignocellulosic residues derived from the Brazilian juice processing industry, and their prospects for bioenergy production.

\section{Experimental}

\section{Collection and preparation}

The apple bagasse, orange bagasse, and cashew-apple bagasse were obtained locally in João Pessoa, Brazil. The sample preparation procedure was performed individually for each sample. Each sample was pulverized in a knives mill (Solab, SL-31, Piracicaba, Brazil). Subsequently, the sample was sieved using a mechanical sieve shaker (Bertel, series 1.0, São Paulo, Brazil) to obtain a particle size less than $106 \mu \mathrm{m}(<140 \mathrm{mesh})$. Each pulverized sample was stored in airtight containers for further physicochemical characterization.

\section{Physicochemical characterization}

In this study, the potential of apple bagasse, orange bagasse and cashew-apple bagasse as alternatives biofuels 
applied in thermochemical processes was investigated experimentally in terms of proximate analysis, ultimate analysis, high heating value (HHV) and bulk density. By using experimental characteristics, other energy-related parameters were calculated, including atomic molar ratio, biochemical composition, low heating value (LHV), bioenergy density, fuel value index (FVI), fossil fuel equivalence and potential $\mathrm{CO}_{2}$ retention. The standards protocols and measurement equipment employed for physicochemical characterization are summarized in Table 1. Three repetitions under each characterization analysis were carried out to achieve a satisfactory reproducibility, hence the results show average values.

\section{Proximate analysis}

Proximate analysis was performed to determine moisture (MO), volatile matter (VM), fixed carbon (FC) and ash (ASH) content following the heating programming (Table 2) found in related literature, ${ }^{17,26-29}$ which is an adaptation of standard protocols as described in ASTM E1131 $1^{20}$ using a thermogravimetric analyzer TGA-Q50 TA Instruments, manufactured at New Castle, United States, while the fixed carbon was calculated by the difference using equation $1,{ }^{30}$ shown below:

$\mathrm{FC}(\%)=100 \%-\mathrm{MO}(\%)-\mathrm{VM}(\%)-\mathrm{ASH}(\%)$

\section{Ultimate analysis}

The ultimate (elemental) analysis was performed for determining the percentages of carbon, hydrogen, nitrogen, sulfur and oxygen (calculated by the difference) in each feedstock. Analysis to determine the mass content of carbon $(\mathrm{C})$, hydrogen $(\mathrm{H})$ and nitrogen $(\mathrm{N})$ was performed according to ASTM D5373, ${ }^{21}$ using an Elemental Analyzer 2400 CHN PerkinElmer Series II (Shelton, United States). The quantification of sulfur mass content was performed based on standard ASTM D4239, ${ }^{22}$ using an inductively coupled plasma optical emission spectrometer (ICP OES Analyzer, Spectro Arcos, Mahwah, United States). The mass content of oxygen $(\mathrm{O})$ in the feedstock composition was determined by the difference using equation $2,{ }^{26}$ all values on dry basis.

$\mathrm{O}(\%)=100-\mathrm{C}(\%)-\mathrm{H}(\%)-\mathrm{N}(\%)-\mathrm{S}(\%)-\mathrm{ASH}(\%)$

\section{Atomic molar ratio}

The hydrogen over carbon ratio $(\mathrm{H} / \mathrm{C})$ and oxygen over carbon ratio $(\mathrm{O} / \mathrm{C})$ were calculated using the ultimate analysis and molar mass of carbon $\left(12 \mathrm{~kg} \mathrm{kmol}^{-1}\right)$, hydrogen $\left(1 \mathrm{~kg} \mathrm{kmol}^{-1}\right)$ and oxygen $\left(16 \mathrm{~kg} \mathrm{kmol}^{-1}\right)$, as follows: ${ }^{31}$

$\mathrm{H} / \mathrm{C}=\frac{\mathrm{H}(\%) / 1}{\mathrm{C}(\%) / 12}$

Table 1. Standards applied and measurement equipment used for comprehensive characterization of apple bagasse, cashew-apple bagasse and orange bagasse

\begin{tabular}{|c|c|c|}
\hline Parameter & Standard & Measurement equipment \\
\hline Moisture / \% & ASTM E- $1131^{20}$ & TGA-Q50 TA Instruments \\
\hline Volatile matter / \% & ASTM E- $1131^{20}$ & TGA-Q50 TA Instruments \\
\hline Ash / \% & ASTM E- $1131^{20}$ & TGA-Q50 TA Instruments \\
\hline Carbon / \% & ASTM D5373-02 21 & Elemental Analyzer 2400 CHN PerkinElmer Series II \\
\hline Hydrogen / \% & ASTM D5373-02 21 & Elemental Analyzer 2400 CHN PerkinElmer Series II \\
\hline Nitrogen / \% & ASTM D5373-02 & Elemental Analyzer 2400 CHN PerkinElmer Series II \\
\hline Sulfur / \% & ASTM D4239-1722 & ICP OES Analyzer \\
\hline $\mathrm{HHV} /\left(\mathrm{MJ} \mathrm{kg}^{-1}\right)$ & ASTM D5865 23 & calorimeter bomb IKA C200 \\
\hline Bulk density / $\left(\mathrm{kg} \mathrm{m}^{-3}\right)$ & ASTM E873-82 24 & graduated cylinder \\
\hline
\end{tabular}

TGA: thermogravimetric analyzer; ICP OES: inductively coupled plasma optical emission spectroscopy; HHV: higher heating value.

Table 2. Heating programming used for proximate analysis ${ }^{25}$

\begin{tabular}{|c|c|c|c|c|c|}
\hline Step & Gas & Gas flow / $\left(\mathrm{mL} \mathrm{min}^{-1}\right)$ & Heating rate $/\left({ }^{\circ} \mathrm{C} \mathrm{min}{ }^{-1}\right)$ & Temperature $/{ }^{\circ} \mathrm{C}$ & Residence time / min \\
\hline 1 & nitrogen & \multirow{4}{*}{100} & 50 & 50 & 5 \\
\hline 2 & nitrogen & & 50 & 110 & 5 \\
\hline 3 & nitrogen & & 90 & 575 & 15 \\
\hline 4 & synthetic air & & 0.1 & 575 & mass constant \\
\hline
\end{tabular}


$\mathrm{O} / \mathrm{C}=\frac{\mathrm{O}(\%) / 16}{\mathrm{C}(\%) / 12}$

\section{Biochemical composition}

Biochemical composition analysis was conducted to estimate cellulose, hemicellulose, lignin and extractives content. The mass fractions of cellulose and lignin were estimated according to the Sheng and Azevedo ${ }^{32}$ correlations, which is acceptable for a large range of biomass samples. These correlations can be applied to biomass with atomic molar ratios $\mathrm{O} / \mathrm{C}$ from 0.56 to $0.83, \mathrm{H} / \mathrm{C}$ from 1.26 to 1.69 , and VM from 73 to $86 \%$ (in dry ash-free basis), using equation $5^{32,33}$ (cellulose) and equation $6^{32,33}$ (lignin).

$$
\begin{aligned}
& \text { Cellulose }=-1019.07+293.810(\mathrm{O} / \mathrm{C})-187.639(\mathrm{O} / \mathrm{C})^{2} \\
& +65.1426(\mathrm{H} / \mathrm{C})-19.3025(\mathrm{H} / \mathrm{C})^{2}+21.7448(\mathrm{VM})- \\
& 0.132123(\mathrm{VM})^{2}
\end{aligned}
$$

Lignin $=612.099+195.366(\mathrm{O} / \mathrm{C})-156.535(\mathrm{O} / \mathrm{C})^{2}+$ $511.357(\mathrm{H} / \mathrm{C})-177.025(\mathrm{H} / \mathrm{C})^{2}-24.3224(\mathrm{VM})+$ $0.145306(\mathrm{VM})^{2}$

The hemicellulose and extractives fractions can be calculated using the equation $7,{ }^{33}$ and equation $8^{4}$ (by the difference), respectively.

Hemicellulose $=\mathrm{VM}-$ Cellulose - Lignin

Extractives $=100 \%-$ Cellulose - Lignin -

Hemicellulose

\section{Calorific values}

$\mathrm{HHV}$ was measured using an adiabatic bomb calorimeter model C200 (IKA, Wilmington, United States), according to standard ASTM D5865. ${ }^{23}$ Lower heating value (LHV) can then be calculated based on HHV and mass content of hydrogen, taking into account the energy loss involved with the heat consumption by water, as follows: ${ }^{26}$

$$
\operatorname{LHV}\left(\mathrm{MJ} \mathrm{kg}^{-1}\right)=\operatorname{HHV}\left(\mathrm{MJ} \mathrm{kg}^{-1}\right)-0.2183 \mathrm{H}(\%)
$$

\section{Bulk density}

Bulk density was determined by measuring the weight of the sample $(\mathrm{g})$ and dividing it by the volume $\left(\mathrm{cm}^{3}\right)$, using a graduated cylinder as mentioned in standard protocol ASTM E873-82. ${ }^{24}$

\section{Bioenergy density}

The bioenergy density was calculated by multiplying the bulk density by HHV, which can be obtained by equation $10 .{ }^{19}$
Bioenergy density $\left(\mathrm{MJ} \mathrm{m}^{-3}\right)=$ Bulk density $\left(\mathrm{kg} \mathrm{m}^{-3}\right) \times$ $\mathrm{HHV}\left(\mathrm{MJ} \mathrm{kg}^{-1}\right)$

\section{Fuel value index}

The characteristic parameters used to evaluate the FVI were HHV, bulk density and ash content. In this performance index, the HHV and bulk density are positive parameters, and ash content is a negative parameter. ${ }^{34} \mathrm{FVI}$ of juice processing residues on a dry basis was calculated by equation $11 .{ }^{19}$

$\mathrm{FVI}=\frac{\text { Bulk density }\left(\mathrm{kg} \mathrm{m}^{-3}\right) \times \mathrm{HHV}\left(\mathrm{MJ} \mathrm{kg}^{-1}\right)}{\mathrm{ASH}(\%)}$

\section{Fossil fuel equivalence}

Using as basis the approximate values of energy density for fossil fuels such as petroleum $\left(37.03 \mathrm{GJ} \mathrm{m}^{-3}\right)$, diesel fuel $\left(36.27 \mathrm{GJ} \mathrm{m}^{-3}\right)$, fuel oil $\left(39.93 \mathrm{GJ} \mathrm{m}^{-3}\right)$ and gasoline $\left(32.62 \mathrm{GJ} \mathrm{m}^{-3}\right.$ ) found in related literature, ${ }^{4}$ it is possible to estimate the equivalent volume of fossil fuels per cubic meter of apple bagasse, orange bagasse and cashew-apple bagasse (individually). In other words, this enables the obtention of the amount of liquid fossil fuel required to produce the equivalent amount of energy produced by juice processing residues. ${ }^{4}$

Equivalent volume $\left(\mathrm{m}^{-3}{ }_{\text {(fossil fuel) }} \times \mathrm{m}^{-3}\right.$ (biomass) $)=\frac{\text { Bioenergy density } \text { biomass }_{\left(\mathrm{GJ} \mathrm{m}^{-3}\right)}}{\left.\text { Energy density } \text { fossil fuel }_{\text {fu m}}{ }^{-3}\right)}$

\section{Potential $\mathrm{CO}_{2}$ retention}

Finally, to estimate the mass of $\mathrm{CO}_{2}(\mathrm{~kg})$ prevented from being released from fossil fuels, the emission factor of each fossil fuel $\left(\mathrm{kg} \mathrm{CO}_{2} \mathrm{~L}^{-1}\right)$ was used, disregarding the $\mathrm{CO}_{2}$ emissions from the production, harvesting, and transportation of the biomass. The reference values for the emission factor of typical fossil fuels such as petroleum (37.03 $\left.\mathrm{GJ} \mathrm{m}^{-3}\right)$, diesel fuel $\left(36.27 \mathrm{GJ} \mathrm{m}^{-3}\right)$, fuel oil $\left(39.93 \mathrm{GJ} \mathrm{m}^{-3}\right)$ and gasoline $\left(32.62 \mathrm{GJ} \mathrm{m}^{-3}\right)$ were obtained in the scientific literature. ${ }^{4}$ Potential $\mathrm{CO}_{2}$ retention was calculated from the emission factor (EF) using the equation $13 .{ }^{4}$

Potential $\mathrm{CO}_{2}$ retention $\left(\mathrm{kg}_{\mathrm{CO}_{2}}\right)=\mathrm{EF}\left(\mathrm{kg}_{\mathrm{CO}_{2}} \mathrm{~L}^{-1}\right) \times$ Equivalent volume(L)

\section{Results and Discussion}

According to proximate composition (Figure 1), raw samples of apple bagasse, cashew-apple bagasse and orange bagasse contained moisture contents of 7.88, 8.17 and $9.23 \mathrm{wt} . \%$, respectively, which is tolerable for combustion purposes. ${ }^{19}$ 


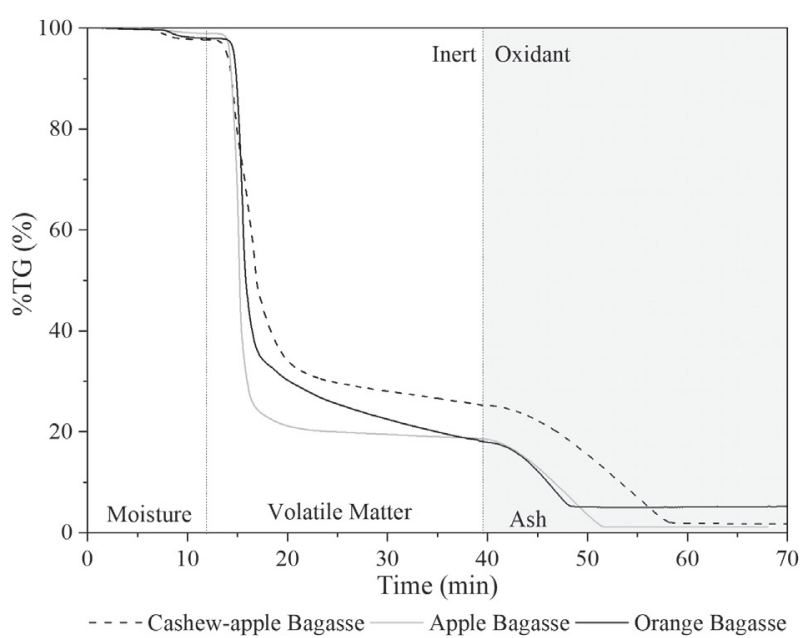

Figure 1. Thermogravimetric analysis curves for proximate analysis of juice processing residues.

The energy-related characteristics obtained for apple bagasse, orange bagasse and cashew-apple bagasse are summarized in Table 3. Among the juice processing residues, apple bagasse contains the highest volatile matter $(80.55 \%)$, whereas cashew-apple bagasse and orange bagasse contain less than $74 \%$ of volatile matter (in dry mass). Therefore, in comparison with cashew-apple bagasse and orange bagasse, apple bagasse has a better ignition potential at low temperatures, implying high reactivity and enriched combustion process. ${ }^{35}$ This characteristic could also be convenient for volatiles recovery, i.e., biooil and pyrolytic syngas production from apple bagasse using fast pyrolysis (both of which are useful biofuels). ${ }^{36}$ On the other hand, cashew-apple bagasse and orange bagasse have a higher amount of fixed carbon (24.18 and $20.60 \%$, respectively) than that of apple bagasse $(17.66 \%)$. This considerable fixed carbon content is a remarkable characteristic that can result in high yielding biochar production through slow pyrolysis; the obtained biochar can be used for subsequent gasification or as a low-cost adsorbent for environmental applications. ${ }^{37}$

The higher volatile matter-fixed carbon ratio in juice processing residues (>3) compared to that of low-rank coals $(<1)^{38,39}$ outlined that combustion of juice processing residues will take place predominantly in the gas-phase involving volatile combustion. ${ }^{40}$ Regarding the amount of ash (Table 3), it was observed that juice processing residues show less ash content $(<6 \%)$ than that of subbituminous and lignite coals $(>9.7 \%){ }^{38,39}$ The occurrence of low ash content is an attractive attribute to minimize the emergence of unwanted problems such as fouling and scaling in the

Table 3. Comprehensive characterization for apple bagasse, cashew-apple bagasse, and orange bagasse

\begin{tabular}{|c|c|c|c|}
\hline Sample & Apple bagasse & Cashew-apple bagasse & Orange bagasse \\
\hline \multicolumn{4}{|c|}{ Proximate analysis / wt. $\%$} \\
\hline Moisture $^{\mathrm{a}}$ & $7.88 \pm 1.18$ & $8.17 \pm 0.89$ & $9.23 \pm 0.80$ \\
\hline Volatile matter ${ }^{\mathrm{b}}$ & $80.55 \pm 0.57$ & $73.98 \pm 0.59$ & $73.20 \pm 0.61$ \\
\hline Fixed carbon ${ }^{\mathrm{b}}$ & $17.66 \pm 0.22$ & $24.18 \pm 0.31$ & $20.60 \pm 0.27$ \\
\hline $\mathrm{Ash}^{\mathrm{b}}$ & $1.79 \pm 0.33$ & $1.84 \pm 0.28$ & $6.20 \pm 0.34$ \\
\hline $\mathrm{VM} / \mathrm{FC}$ & 4.56 & 3.06 & 3.55 \\
\hline \multicolumn{4}{|c|}{ Ultimate analysis / wt. $\%$} \\
\hline Carbon $^{\mathrm{b}}$ & $49.89 \pm 0.32$ & $44.89 \pm 0.29$ & $46.40 \pm 0.35$ \\
\hline Hydrogen ${ }^{\mathrm{b}}$ & $6.56 \pm 0.15$ & $6.34 \pm 0.13$ & $5.54 \pm 0.11$ \\
\hline Nitrogen ${ }^{b}$ & $1.56 \pm 0.05$ & $2.76 \pm 0.09$ & $1.70 \pm 0.04$ \\
\hline Sulfur ${ }^{\mathrm{b}}$ & $<0.01$ & $<0.01$ & $<0.01$ \\
\hline Oxygen $^{b}$ & $40.19 \pm 0.28$ & $44.16 \pm 0.18$ & $40.15 \pm 0.20$ \\
\hline \multicolumn{4}{|c|}{ Atomic molar ratio } \\
\hline $\mathrm{H} / \mathrm{C}$ & 1.58 & 1.69 & 1.43 \\
\hline $\mathrm{O} / \mathrm{C}$ & 0.60 & 0.74 & 0.65 \\
\hline \multicolumn{4}{|c|}{ Biochemical composition / wt.\% } \\
\hline Cellulose $^{c}$ & 49.89 & 37.64 & 40.33 \\
\hline Hemicellulose $\mathrm{e}^{\mathrm{c}}$ & 16.58 & 16.27 & 8.66 \\
\hline Lignin $^{\mathrm{c}}$ & 21.71 & 21.46 & 29.04 \\
\hline Extractives $^{\mathrm{c}}$ & 17.98 & 24.63 & 21.96 \\
\hline
\end{tabular}

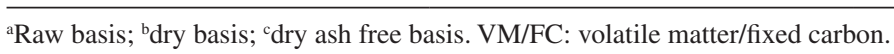


thermal conversion processes. ${ }^{16}$ The results from proximate analysis are comparable to a range of biomasses used as solid biofuels. $^{35}$

Ultimate analysis (Table 3 ) in terms of carbon content (44.9 to $49.9 \%$ ), hydrogen content (5.5 to $6.6 \%$ ) and oxygen content (40.1 to $44.2 \%$ ) indicated a promising applicability for thermal systems when compared to several solid biomass. ${ }^{41}$ In addition, juice processing residues have a lower content of sulfur compared to lignite and subbituminous coals $(0.51-2.70 \%),{ }^{38,39}$ while nitrogen content was lower in other researches on biomass materials. ${ }^{36,42,43}$ The significance of these low contents is that the possibility of toxic emissions $\left(\mathrm{NO}_{\mathrm{X}}\right.$ and $\left.\mathrm{SO}_{\mathrm{X}}\right)$ from the thermal conversion of juice processing residues is minimized, thus not contributing to the formation of acid rains or the depletion of the ozone layer. ${ }^{28}$

The H/C and O/C molar ratios obtained for juice processing residues varied (respectively) from 1.43 to 1.69 and from 0.60 to 0.74 , as presented in Table 3 . The relation between $\mathrm{O} / \mathrm{C}$ and $\mathrm{H} / \mathrm{C}$ observed by the Van Krevelen diagram (Figure 2) indicates that apple bagasse, cashewapple bagasse and orange bagasse are in the region typical for biomass. It was found that the $\mathrm{O} / \mathrm{C}$ molar ratio is lower for apple bagasse (0.60); hence it is possible to infer that apple bagasse is expected to have a higher energy profile. ${ }^{19}$ When compared to lignite and subbituminous coals (H/C ca. 1.22), ${ }^{38,39}$ the $\mathrm{H} / \mathrm{C}$ molar ratios for juice processing residues are comparatively higher, which implies lower $\mathrm{CO}_{2}$ emissions with higher energy efficiency on its combustion. ${ }^{6}$ The highest $\mathrm{O} / \mathrm{C}$ ratio was associated with cashew-apple bagasse (0.74), thus making it possible to infer that cashewapple bagasse has more hydroxyl, carboxyl, ether, and ketone functional groups in its chemical structure. ${ }^{44}$

The $\mathrm{H} / \mathrm{C}$ and $\mathrm{O} / \mathrm{C}$ molar ratios found are in accordance with expected values for lignocellulosic biomass (0.62-1.96

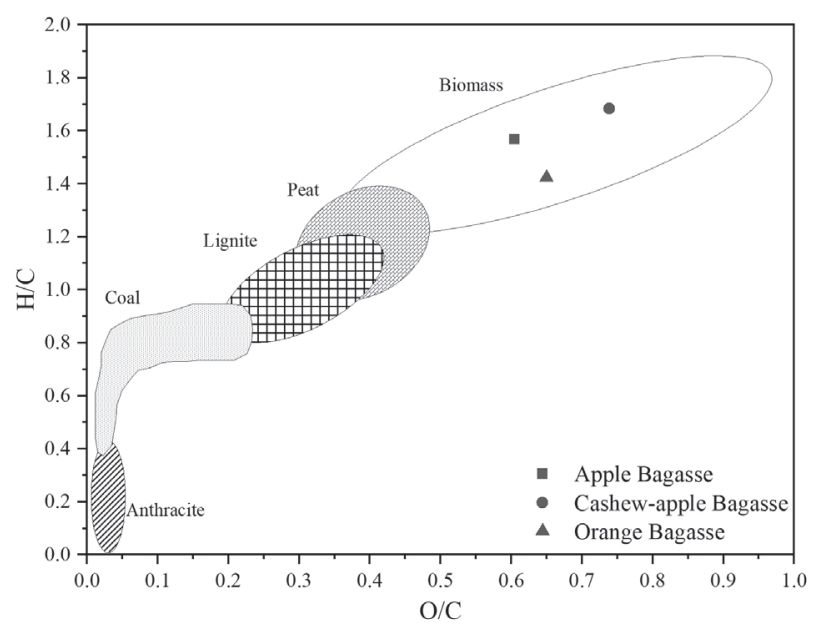

Figure 2. Van Krevelen diagram for juice processing residues in comparison with solid fuels. and $0.34-1.19$, respectively). ${ }^{33}$ Typically, high-rank coal accommodates more higher energy compared to biomass because of high $\mathrm{C}$, low $\mathrm{O}$ and $\mathrm{O} / \mathrm{C}$ ratio. ${ }^{19}$ Therefore, blending biomass with high-quality coal in the form of pellets can be a promising approach for improved combustion performance. ${ }^{18,45}$

Information on the biochemical structure, in terms of relative contents of cellulose, hemicellulose, lignin and extractives, is needed to better support potential applications. As referred to in Table 3, the mass fractions of cellulose (37.6-49.9\%), hemicellulose (8.7-16.6\%), and extractives (18.0-24.7\%) conform with other lignocellulosic biomass. ${ }^{46,47}$ On the other hand, the measured lignin contents varied from 21.71 to $29.04 \%$ (in dry ash-free basis), with a high lignin content indicating that the thermal route is the most preferred for the conversion of these lignocellulosic residues. ${ }^{47}$ For comparison purposes, agricultural biomass wastes such as corn straws, corn cob, sugarcane bagasse and Jatropha seed cakes have lignin contents below 16\%. ${ }^{46}$ In contrast, higher cellulose and hemicellulose contents are often preferred for biochemical conversion processes. ${ }^{47}$ It is suggested that biomass with high lignin content produces a condensable pyrolysis product (bio-oil) enriched in phenolic compounds. ${ }^{48}$ Therefore, lignocellulosic residues from the Brazilian juice processing industry have a high potential to produce valuable hydrocarbons (phenolic compounds) through fast pyrolysis.

The HHV for juice processing residues varied from 16.53 to $18.72 \mathrm{MJ} \mathrm{kg}^{-1}$ (Table 4), which is higher than the HHV reported for other lignocellulosic biomass, such as rice husk, ponkan peel, sugarcane bagasse, elephant grass, cotton stalk, wood sawdust and arecanut husk..$^{4,17,27,50-52}$ On the other hand, the LHV reflects in practice the maximum amount of bioenergy that can be produced from biomass combustion, and the bioenergy potential recoverable from juice processing residues varied from 15.24 to $17.03 \mathrm{MJ} \mathrm{kg}^{-1}$. By combining a considerable bioenergy potential with a great abundance of these feedstocks, it is posited that juice processing residues have the potential to compete favorably with low-rank coals.

Bulk density is a key characteristic in the development of an adequate logistics strategy for biomass handling and transport. ${ }^{53}$ As noted in Table 4, the bulk density order for the studied lignocellulosic residues was orange bagasse $\left(553.67 \mathrm{~kg} \mathrm{~m}^{-3}\right)>$ apple bagasse $\left(360.84 \mathrm{~kg} \mathrm{~m}^{-3}\right)>$ cashew-apple bagasse $\left(237.70 \mathrm{~kg} \mathrm{~m}^{-3}\right)$. The bulk density of orange bagasse is higher than other well-known biomass residues such as rice husk, coconut shell, ponkan peel, sugarcane bagasse, elephant grass, cotton stalk and arecanut husk. ${ }^{4,17,49-52}$ Usually, a higher bulk density value implies low costs for storage, transportation and handling. 
Table 4. Comparison of calorific values, bulk density and bioenergy density of apple bagasse, cashew-apple bagasse, and orange bagasse with other lignocellulosic wastes

\begin{tabular}{lcccc}
\hline Sample & $\mathrm{HHV}^{\mathrm{a}} /\left(\mathrm{MJ} \mathrm{kg}^{-1}\right)$ & $\mathrm{LHV}^{\mathrm{a}, \mathrm{b}} /\left(\mathrm{MJ} \mathrm{kg}^{-1}\right)$ & Bulk density $^{\mathrm{a}}\left(\mathrm{kg} \mathrm{m}^{-3}\right)$ & Bioenergy density $^{\mathrm{a}, \mathrm{c}} /\left(\mathrm{GJ} \mathrm{m}^{-3}\right)$ \\
\hline Apple bagasse & $18.72 \pm 0.05$ & 16.83 & $360.84 \pm 4.50$ & 6.75 \\
Cashew-apple bagasse & $16.53 \pm 0.52$ & 15.24 & $237.70 \pm 5.05$ & 3.93 \\
Orange bagasse & $18.16 \pm 0.10$ & 17.03 & $553.67 \pm 6.13$ & 10.05 \\
Rice husk $^{4}$ & 16.18 & 14.61 & 232.52 & 3.76 \\
Coconut shell $^{49}$ & - & - & 293.90 & - \\
Ponkan peel $^{17}$ & 15.51 & 14.22 & 311.00 & 4.82 \\
Sugarcane bagasse $^{50}$ & 15.90 & 14.58 & 160.00 & 2.54 \\
Cotton stalk $^{50}$ & 17.40 & 16.40 & 310.00 & 5.39 \\
Elephant grass $^{51}$ & 15.61 & 14.29 & 230.00 & 3.59 \\
Wood sawdust $^{27}$ & 15.05 & 13.83 & - & - \\
Arecanut husk $^{52}$ & 16.98 & 15.82 & 200.00 & 3.40 \\
\hline
\end{tabular}

${ }^{\mathrm{a}}$ Dry basis; ${ }^{\mathrm{b}}$ calculated by equation 9 ; ' ${ }^{c}$ alculated by equation 10 . HHV: higher heating value; LHV: lower heating value.

Another important factor connected with handling and transportation is the bioenergy density, which represents the available potential bioenergy relative to the biomass volume. In particular, the apple bagasse and orange bagasse have been shown to have a high bioenergy density $(6.75$ and $10.05 \mathrm{GJ} \mathrm{m}^{-3}$, respectively) as compared to rice husk, ponkan peel, sugarcane bagasse, elephant grass, cotton stalk and arecanut husk, ${ }^{4,17,50-52}$ hence indicating high applicability of these juice processing residues for bioenergy production with greater transport efficiency and lower transport costs.

Concerning FVI, it is an insightful parameter for screening suitable biofuels. As noted in Table 5, FVI for apple bagasse, cashew-apple bagasse and orange bagasse are comparable to typical biomass for bioenergy purposes. ${ }^{4,17,50-52}$ Therefore it is expected that juice processing residues (higher FVI values) possess better biofuel properties in terms of flammability and heat generation..$^{54,55}$
In an effort to obtain information about fossil fuel equivalence and potential $\mathrm{CO}_{2}$ retention, both the energy density and the emission factor for conventional liquid fossil fuels (e.g., petroleum, diesel fuel, fuel oil and gasoline) were used following the procedure found in related literature. ${ }^{4}$ Fossil fuel equivalence (Figure 3a) and potential $\mathrm{CO}_{2}$ retention (Figure $3 \mathrm{~b}$ ) ought to be considered for establishing the main characteristics of biofuels. Compared to apple bagasse and cashew-apple bagasse, orange bagasse has the higher equivalent in fossil fuel volume, as mentioned in Figure 3a. In this sense, $1 \mathrm{~m}^{3}$ of orange bagasse is able to replace approximately $255 \mathrm{~L}$ of petroleum, $260 \mathrm{~L}$ of diesel oil, $236 \mathrm{~L}$ of fuel oil or $289 \mathrm{~L}$ of gasoline to produce an equal amount of energy. The results of fossil fuel equivalence indicated that orange bagasse and apple bagasse gave better equivalence characteristics than well-known lignocellulosic biomass such as forestry wastes, rice husk, coffee wastes, sugarcane bagasse, maize

Table 5. Comparison of FVI of apple bagasse, cashew-apple bagasse, and orange bagasse with other lignocellulosic wastes

\begin{tabular}{lcccc}
\hline Sample & $\mathrm{Ash}^{\mathrm{a}} / \%$ & $\mathrm{HHV}^{\mathrm{a}} /\left(\mathrm{MJ} \mathrm{kg}^{-1}\right)$ & ${\text { Bulk density } /\left(\mathrm{kg} \mathrm{m}^{-3}\right)}^{\mathrm{FVI}\left(\times 10^{3}\right)^{\mathrm{a}, \mathrm{b}}}$ \\
\hline Apple bagasse & 1.79 & 18.72 & 360.84 & 3.77 \\
Cashew-apple bagasse & 1.84 & 16.53 & 237.70 & 2.14 \\
Orange bagasse & 6.20 & 18.16 & 553.67 & 1.62 \\
Rice husk $^{4}$ & 16.80 & 16.18 & 232.52 & 0.22 \\
Ponkan peel $^{17}$ & 2.20 & 15.51 & 311.00 & 2.19 \\
Sugarcane bagasse $^{50}$ & 5.20 & 17.70 & 140.00 & 0.48 \\
Cotton stalk $^{50}$ & 5.10 & 17.40 & 310.00 & 1.06 \\
Elephant grass $^{51}$ & 7.67 & 17.35 & 255.67 & 0.58 \\
Arecanut husk $^{52}$ & 12.00 & 16.98 & 200.00 & 0.28 \\
\hline
\end{tabular}

${ }^{\mathrm{a}}$ Dry basis; ${ }^{\mathrm{b}}$ calculated by equation 11 . HHV: higher heating value; FVI: fuel-value-index. 
wastes and bamboo. ${ }^{4}$ The use of lignocellulosic biomass for bioenergy has a neutral carbon balance. In other words, the carbon consumed in the energetic process is returned to biomass formation within a short time, compared to fossil fuels. ${ }^{37}$ Among the juice processing residues, the highest potential of reduction in $\mathrm{CO}_{2}$ emissions would be achieved by substituting liquid fossil fuels for orange bagasse and apple bagasse. This estimate must be valid at the moment when fossil fuels (primarily fuel oil and diesel) have been replaced by biomass for electricity and heat production.
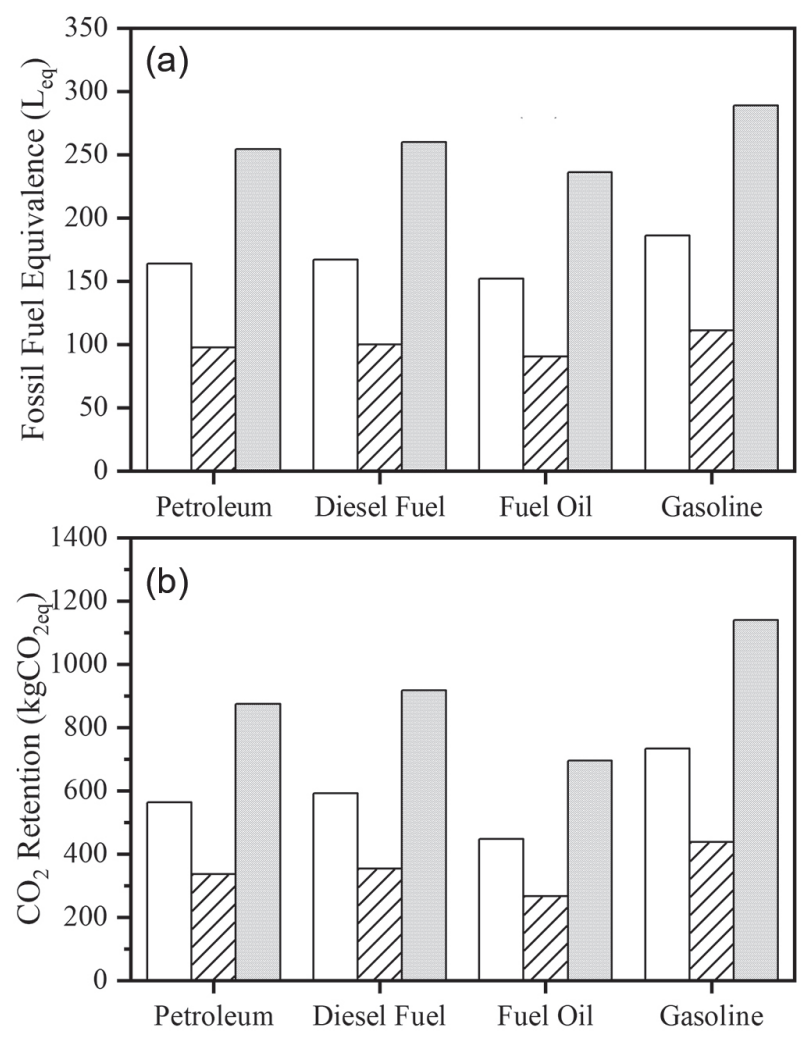

Apple Bagasse V7 Cashew Apple Bagasse $\square$ Orange Bagasse

Figure 3. (a) Fossil fuels equivalence (L) (equal to $1 \mathrm{~m}^{3}$ of biomass) and (b) potential $\mathrm{CO}_{2}$ retention $(\mathrm{kg})$ from fossil fuels saved by juice processing residues.

Traditionally, the uses of coals from Brazil for energy purposes is limited due to its low calorific value, high ash and high sulfur contents. ${ }^{4,38}$ Recent studies ${ }^{18,45}$ are gaining interest in the co-utilization of lignocellulosic feedstock with high-rank coals in the form of pellets. Until now, juice processing residues remain underexplored for bioenergy production, which constitutes a substantial loss of abundant, cheap and readily available raw material that could be used for the production of different energyrich products. Therefore, blending apple bagasse, orange bagasse and cashew-apple bagasse with coal may be an efficient combination for obtaining bioenergy, as well as the acquisition of carbon credits. Additionally, the large-scale thermal conversion of apple bagasse, orange bagasse, and cashew-apple bagasse may eventually lead to high costs for transportation and logistics, which are also reduced with co-pelletization. Attention is drawn to the need of quantifying the energy balance of juice processing residues thermal conversion in terms of economic and environmental impacts, in order to determine if its thermochemical conversion is economically feasible, in line with related literature. ${ }^{56}$ In summary, promising characteristics of apple bagasse, orange bagasse and cashew-apple bagasse make these lignocellulosic residues from the Brazilian juice processing industry particularly attractive for use as biofuels on potential applications in thermochemical processes.

\section{Conclusions}

This work recommends the use of apple bagasse, orange bagasse and cashew-apple bagasse as eco-friendly feedstocks in thermochemical processes. Proximate and ultimate analyses indicated a favorable applicability for thermochemical processes such as combustion, more so when compared with well-known lignocellulosic residues, as well as emphasizing negligible sulfur concentration and ash contents below 6.5\%. Apple bagasse appears more suitable as biofuel in terms of bulk density, bioenergy density and FVI. In particular, the hydrogen-carbon ratio for juice processing residues (1.43-1.69) was higher than those of low-rank coals (ca. 1.2), which can indicate lower $\mathrm{CO}_{2}$ emissions and higher energy efficiency during its thermal conversion. In short, the insights from this work demonstrate that juice processing residues could be utilized as alternative feedstocks for bioenergy production using thermochemical processes. Thus, producing bioenergy from lignocellulosic residues, rather than disposing of them, is a promising route to complement the national energy supply and a vital step towards zero-waste production in the Brazilian juice processing industry. In Brazil, energy engineers possess years of practical inplant expertise and design of thermochemical facilities used to convert sugarcane wastes to bioenergy, which can be extended for converting juice processing residues to bioenergy. Concerning future prospects, an essential issue that will be explored is the techno-economic evaluation in order to determine if the thermochemical valorization is economically feasible. Finally, the combined use of juice processing residues and high-rank coal via copelletization for better bioenergy output is a promising approach that needs to be deeply investigated in the future as well. 


\section{Acknowledgments}

This work was performed with the support of the Brazilian Council for Scientific and Technological Development, Process 423869/2016-7 (Conselho Nacional de Desenvolvimento Científico e Tecnológico, CNPq), the Brazilian Coordination for the Improvement of Higher Education Personnel, finance code 001 (Coordenação de Aperfeiçoamento de Pessoal de Nível Superior, CAPES) and Research Support Foundation of the State of Paraíba (Fundação de Apoio à Pesquisa do Estado da Paraíba, FAPESQ-PB). Jônatas G. R. Martins provided English editing of the manuscript.

\section{Author Contributions}

José L. F. Alves and Emmely O. da Trindade conducted the characterization, data analysis, and prepared the first draft of the manuscript; Jean C. G. da Silva, Guilherme D. Mumbach and Ricardo F. Alves helped in the analysis and interpretation of the data; José M. Barbosa Filho, Petrônio F. de Athayde-Filho, and Rennio F. de Sena provided the resources and supervised the work. All authors have participated in drafting the article and/or revising it critically for scientific content and approved the manuscript for submission.

\section{References}

1. Santos, L. O.; Silva, F. F.; Santos, L. C.; Carregosa, I. S. C.; Wisniewski Jr., A.; J. Braz. Chem. Soc. 2018, 29, 151.

2. Bueno, C. C.; Maia, A. A. D.; de Morais, L. C.; Rosa, A. H.; J. Braz. Chem. Soc. 2017, 28, 2202.

3. Singh, Y. D.; Mahanta, P.; Bora, U.; Renewable Energy 2017, 103, 490

4. Protásio, T. P.; Bufalino, L.; Tonoli, G. H. D.; Junior, M. G.; Trugilho, P. F.; Mendes, L. M.; BioResources 2013, 8, 1166.

5. Veiga, J. P. S.; Valle, T. L.; Feltran, J. C.; Bizzo, W. A.; Renewable Energy 2016, 93, 691.

6. Silva, A. V. S.; Torquato, L. D. M.; Cruz, G.; Waste Manage. 2019, 100, 91.

7. Braga, R. M.; Queiroga, T. S.; Calixto, G. Q.; Almeida, H. N.; Melo, D. M. A.; Melo, M. A. F.; Freitas, J. C. O.; Curbelo, F. D. S.; Environ. Sci. Pollut. Res. 2015, 22, 18987.

8. Virmond, E.; de Sena, R. F.; Albrecht, W.; Althoff, C. A.; Moreira, R. F. P. M.; José, H. J.; Waste Manage. 2012, 32, 1952.

9. http://www.fao.org/faostat/en/\#data/QC, using filters "Brazil", "Production Quantity" and "2017" for different fruits, accessed in October 2019.

10. Bravo, S. M. E.; Morales, M.; del Mónaco, S. M.; Caballero, A. C.; J. Appl. Microbiol. 2019, 126, 1414.
11. Dhillon, G. S.; Kaur, S.; Brar, S. K.; Renewable Sustainable Energy Rev. 2013, 27, 789.

12. Macagnan, F. T.; dos Santos, L. R.; Roberto, B. S.; de Moura, F. A.; Bizzani, M.; da Silva, L. P.; Bioact. Carbohydr. Diet. Fibre 2015, 6,1 .

13. Correia, J. A. C.; Júnior, J. E. M.; Gonçalves, L. R. B.; Rocha, M. V. P.; Bioresour. Technol. 2013, 139, 249.

14. Santos, R. P.; Santiago, A. A. X.; Gadelha, C. A. A.; Cajazeiras, J. B.; Cavada, B. S.; Martins, J. L.; Oliveira, T. M.; Bezerra, G. A.; Santos, R. P.; Freire, V. N.; J. Food Eng. 2007, 79, 1432.

15. da Silva, L. J. V. B.; dos Santos, I. F. S.; Mensah, J. H. R.; Gonçalves, A. T. T.; Barros, R. M.; Renewable Energy 2020, 149, 1386.

16. da Silva Filho, V. F.; Batistella, L.; Alves, J. L. F.; da Silva, J. C. G.; Althoff, C. A.; Moreira, R. F. P. M.; José, H. J.; Renewable Energy 2019, 141, 402.

17. da Silva, J. C. G.; Andersen, S. L. F.; Costa, R. L.; Moreira, R. F. P. M.; José, H. J.; Biomass Bioenergy 2019, 131, article 105401.

18. Hossain, N.; Morni, N. A. H.; BioEnergy Res. 2019, DOI 10.1007/s12155-019-10061-2.

19. Hossain, N.; BioEnergy Res. 2020, 13, 50.

20. ASTM E1131: Standard Test Method for Compositional Analysis by Thermogravimetry; ASTM International: West Conshohocken, PA, 2003.

21. ASTM D5373: Standard Test Methods for Instrumental Determination of Carbon, Hydrogen, and Nitrogen in Laboratory Samples of Coal and Coke; ASTM International: West Conshohocken, PA, 2002.

22. ASTM D4239-17: Standard Test Method for Sulfur in the Analysis Sample of Coal and Coke Using High-Temperature Tube Furnace Combustion; ASTM International: West Conshohocken, PA, 2017.

23. ASTM D5865: Standard Test Method for Gross Calorific Value of Coal and Coke; ASTM International: West Conshohocken, PA, 2013.

24. ASTM E873-82: Standard Test Method for Bulk Density of Densified Particulate Biomass Fuels; ASTM International: West Conshohocken, PA, 2013.

25. da Silva, J. C. G.; Alves, J. L. F.; Galdino, W. V. A.; Andersen, S. L. F.; de Sena, R. F.; Waste Manage. 2018, 72, 265.

26. Alves, J. L. F.; da Silva, J. C. G.; da Silva Filho, V. F.; Alves, R. F.; Ahmad, M. S.; Ahmad, M. S.; Galdino, W. V. A.; de Sena, R. F.; Bioresour. Technol. 2019, 291, 121892.

27. Pacioni, T. R.; Soares, D.; Di Domenico, M.; Rosa, M. F.; Moreira, R. F. P. M.; José, H. J.; Waste Manage. 2016, 58, 221.

28. Mumbach, G. D.; Alves, J. L. F.; da Silva, J. C. G.; de Sena, R. F.; Marangoni, C.; Machado, R. A. F.; Bolzan, A.; Energy Convers. Manage. 2019, 200, 112031.

29. Domenico, M. D.; Collazzo, G. C.; Pacioni, T. R.; José, H. J.; Moreira, R. F. P. M.; Chem. Eng. Commun. 2019, 206, 158. 
30. Hossain, N.; Jalil, R.; Asia Pac. J. Energy Environ. 2017, 4, 7.

31. Peduzzi, E.; Boissonnet, G.; Maréchal, F.; Fuel 2016, 181, 207.

32. Sheng, C.; Azevedo, J. L. T.; Proc. Combust. Inst. 2002, 29 , 407.

33. Xing, J.; Luo, K.; Wang, H.; Fan, J.; Bioresour. Technol. 2019, 288, 121541.

34. Jain, R. K.; Biomass Bioenergy 1993, 4, 461.

35. García, R.; Pizarro, C.; Lavín, A. G.; Bueno, J. L.; Fuel 2014, $117,1139$.

36. Alves, J. L. F.; da Silva, J. C. G.; da Silva Filho, V. F.; Alves, R. F.; Galdino, W. V. A.; de Sena, R. F.; Biomass Bioenergy 2019, $121,28$.

37. Alves, J. L. F.; da Silva, J. C. G.; da Silva Filho, V. F.; Alves, R. F.; Galdino, W. V. A.; Andersen, S. L. F.; de Sena, R. F.; BioEnergy Res. 2019, 12, 168.

38. Domenico, M. D.; Amorim, S. M.; Collazzo, G. C.; José, H. J.; Moreira, R. F. P. M.; Chem. Eng. Res. Des. 2018, 141, 529.

39. Merdun, H.; Sezgin, İ. V.; Energy 2018, 162, 953.

40. Gao, Y.; Tahmasebi, A.; Dou, J.; Yu, J.; Bioresour. Technol. 2016, 207, 276.

41. Sürmen, Y.; Demirbaş, A.; Energy Sources 2003, 25, 175.

42. Alves, J. L. F.; da Silva, J. C. G.; Mumbach, G. D.; di Domenico, M.; da Silva Filho, V. F.; de Sena, R. F.; Machado, R. A. F.; Marangoni, C.; Renewable Energy 2020, 155, 1328.

43. Alves, J. L. F.; da Silva, J. C. G.; Costa, R. L.; dos Santos Jr., S. F.; da Silva Filho, V. F.; Moreira, R. D. F. P. M.; José, H. J.; J. Therm. Anal. Calorim. 2019, 135, 3269.

44. Baxter, L. L.; Biomass Bioenergy 1993, 4, 85.
45. Hossain, N.; Zaini, J.; Mahlia, T. M. I.; Azad, A. K.; Renewable Energy 2019, 131, 617.

46. Titiloye, J. O.; Abu Bakar, M. S.; Odetoye, T. E.; Ind. Crops Prod. 2013, 47, 199.

47. Loh, S. K.; Energy Convers. Manage. 2017, 141, 285.

48. Bhaskar, T.; Dhyani, V.; Kumar, J.; Awasthi, A.; Biswas, B.; Bioresour. Technol. 2018, 274, 173.

49. Mythili, R.; Venkatachalam, P.; Subramanian, P.; Uma, D.; Bioresour. Technol. 2013, 138, 71.

50. Munir, S.; Daood, S. S.; Nimmo, W.; Cunliffe, A. M.; Gibbs, B. M.; Bioresour. Technol. 2009, 100, 1413.

51. Braga, R. M.; Melo, D. M. A.; Sobrinho, E. V.; Barros, J. M. F.; Melo, M. A. F.; Carvalho, A. F. M.; Fontes, M. S. B.; Freitas, J. C. O.; Catal. Today 2017, 279, 224.

52. Ramesh, S.; Soundarapandian, K.; Karthikeyan, S.; Banu, K. S. P.; Sundararaju, P.; Doraiswamy, U.; Environ. Sci. Pollut. Res. 2019, 26, 3751.

53. Cai, J.; He, Y.; Yu, X.; Banks, S. W.; Yang, Y.; Zhang, X.; Yu, Y.; Liu, R.; Bridgwater, A. V.; Renewable Sustainable Energy Rev. 2017, 76, 309.

54. Ojelel, S.; Otiti, T.; Mugisha, S.; Energy Sustainability Soc. 2015, 5,4 .

55. Hossain, N.; Zaini, J.; Mahlia, T. M. I.; Int. J. Sustainable. Eng. 2019, 12, 123.

56. Hossain, N.; Bhuiyan, M. A.; Pramanik, B. K.; Nizamuddin, S.; Griffin, G.; J. Cleaner Prod. 2020, 255, 120261.

Submitted: December 6, 2019 Published online: May 20, 2020 